\title{
Synthesis and Characterisation of Carbon Nano Materials from Plant Derivative
}

\author{
Geetha Viswanathan, Member, IACSIT, Sanjukta Bhowmik, and Madhuri Sharon
}

\begin{abstract}
Latex of Calotropis was used as precursor for synthesis of Carbon Nano material (CNM) by chemical vapour deposition (CVD) / pyrolysis process. Impact of different carrier gases (Hydrogen, Argon) and catalyst (Nickel, Cobalt, Iron) on morphology of CNM was assessed. It was found that Pyrolysis in presence of Hydrogen produced more defined Carbon Nano beads $(10 \mathrm{~nm}$ to $900 \mathrm{~nm})$ than with Argon which produced agglomerated clusters of spherical nano particles. So far as catalysts are concerned, Nickel gave better Carbon nano beads.
\end{abstract}

Index Terms - Carbon nano material, carrier gas, latex of calotropis, metal nanocatalyst, pyrolysis.

\section{INTRODUCTION}

Usually Carbon Nano Materials (CNMs) are synthesized using petrol derived materials as precursors. These being expensive and at the verge of depletion in the near future, there is a need to look for other sources of precursors to synthesize CNMs. Also according to the principle of green chemistry, the feed stock of any industrial process must be renewable, rather than a depleting natural resource.

Hence, it is a prime requirement to explore regenerative materials for CNM synthesis with high efficiency. Sharon group [1]-[4] has been among the first to synthesize carbon nano tubes (CNT) from plant derived precursors and since then there have been more efforts in this direction. Investigators have started exploring environment-friendly sources of CNMs and established the conditions for growing multi walled carbon nanotubes (MWCNTs), single-wall carbon nanotubes (SWCNTs) and vertically aligned MWCNTs on the suitable catalytic support by a simple and inexpensive chemical vapour deposition (CVD) technique. CNMs have been synthesized by catalytic decomposition of camphor and its analogues, turpentine oil and eucalyptus oil and many more such renewable sources [5]-[12].

Within the wide range of feedstock, the sap of Calotropis plant appears to be promising due to the following reasons: easy availability and good carbon content. To the best of our knowledge plant latex has not been used previously as a CNM precursor.

Chemical vapour deposition (CVD) is the most popular method for producing carbon nanomaterials (CNMs) [13]-

Manuscript received June 5, 2013; revised August 9, 2013. This work was supported by grant from Father Conceicao Rodrigues Institute of Technology(Fr.C.R.I.T.), Vashi, Navi Mumbai.

Geetha Viswanathan and Sanjukta Bhowmik are with Fr. C. R. I. T., Vashi, Navi Mumbai (e-mail: giviswa5@gmail.com, sanjukta12bhowmik@gmail.com).

Madhuri Sharon is with N. S. N. Research Centre for Nanotechnology and Bionanotechnology, Ambernath, Maharashtra (e-mail: sharonmadhuri@gmail.com).
[18]. In this process thermal decomposition of a hydrocarbon vapour is achieved in the presence of a metal catalyst.

For the present work, a modified chemical vapor deposition method has been adopted: pyrolysis. It is similar to chemical vapor deposition method; the only difference is that vaporization and pyrolysis of carbon source occurs simultaneously whereas in CVD it is a two step process. Since these precursors evaporate at relatively higher temperatures, pyrolysis method was adopted for synthesis of CNMs.

For synthesizing CNMs, typically nanometer sized metal particles are required to enable hydrocarbon decomposition at a lower temperature than the spontaneous decomposition temperature of the hydrocarbon [19]-[22]. Most commonly used metals are iron, cobalt, nickel because of two main reasons: i) high solubility of carbon in these metals at high temperatures and ii) high carbon diffusion rate in these metals. Besides that, high melting point and low equilibrium- vapour pressure of these metals offer a wide temperature window of CVD for a wide range of carbon precursors [4].

\section{MAterials AND Method}

Precursor: The latex of Calotropis plant which is a rich source of hydrocarbon was used. Since it contains approximately $80 \%$ moisture it was dried in a muffle furnace at $70^{\circ} \mathrm{C}$ and used as precursor for CNM.

Calotropis sap Analysis: The elemental analysis of the Calotropis sap was done.

Catalyst: Since the objective was to study the impact of different catalysts on the formation of CNM, three different transition metals were selected as catalysts, i.e. Nickel (Ni), Cobalt $(\mathrm{Co})$ and Iron $(\mathrm{Fe})$.

To prepare nano metal catalyst, nitrates of iron, nickel and cobalt were reduced by Urea decomposition method. This process involved conversion of metal Nitrates to metal oxides which was further reduced to nano sized metal particles by Hydrogen.

All the chemicals used were of reagent grade procured from Merck and used as received without any further purification.

Carrier Gas: The carrier gases used were Hydrogen and Argon.

Pyrolysis set-up: Fig. 1 show a schematic diagram of the experimental set-up used for synthesizing CNMs by CVD /pyrolysis method in its simplest form.

The prepared catalyst was sprinkled over the dried sap, in the ratio 1:1000 with respect to the weight of dried sap, in a quartz boat and kept at the centre of a quartz tube which was placed inside a tubular furnace. The carrier gas was 
introduced at the rate of $100 \mathrm{ml}$ per minute into the quartz tube to remove the presence of any oxygen inside the quartz tube. The temperature of the furnace was raised from room temperature to the desired pyrolysis temperature of $900^{\circ} \mathrm{C}$ and flow rate of carrier gas was set at around $25 \mathrm{ml}$ per minute. Pyrolysis was carried out for two hours and thereafter furnace was cooled to room temperature and the CNM deposited in the boat was collected.

The parameters which were varied were the following: catalyst and carrier gas.

The morphology and size of the CNM and metal nano catalysts were assessed using SEM at the SAIF facility of IIT Bombay.

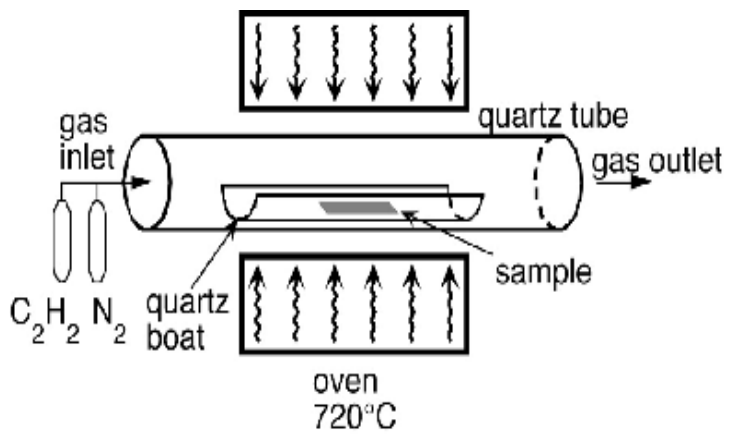

Fig. 1. Schematic diagram of a CVD set-up used for pyrolysis of Calotropis sap.

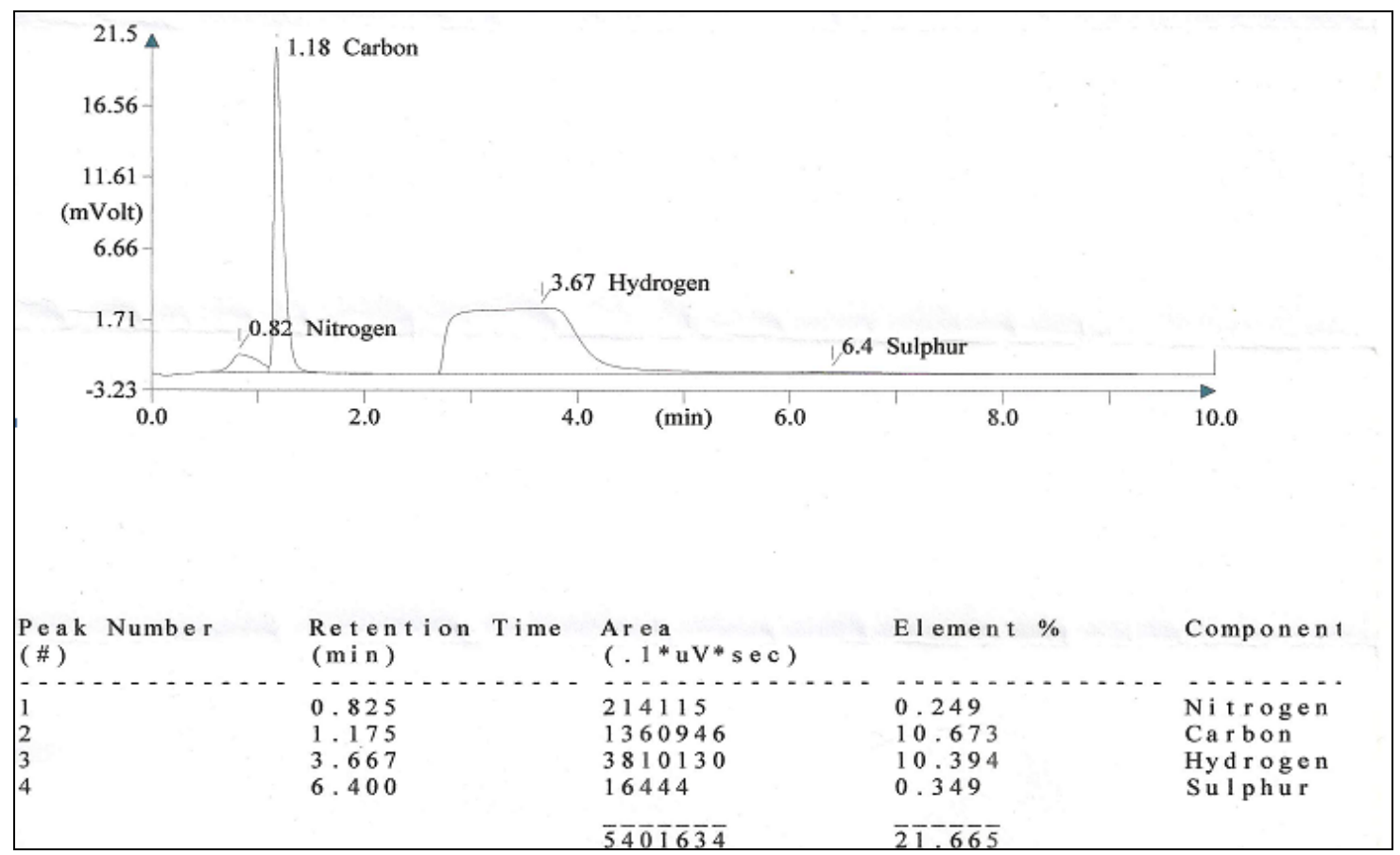

Fig. 2. Elemental composition of Calotropis sap.

\section{RESULTS AND DISCUSSIONS}

Calotropis Sap: The elemental analysis of Calotropis indicates an equal percentage by composition of carbon and Hydrogen apart from nitrogen and sulphur. The results i.e. the chromatogram for sap of Calotropis are presented in Fig. 2 .

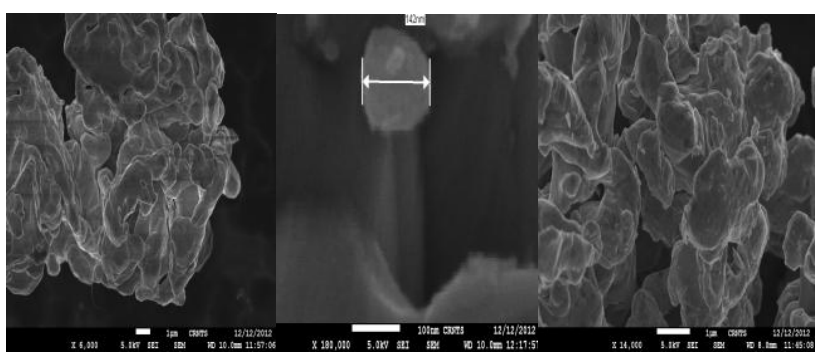

(A)

(B)

(C)

Fig. 3. SEM micrographs of (A) Cobalt (B) Iron and (C) Nickel showing agglomerated spherical nano particle.

Catalyst: The size of metal nanocatalysts plays an important role in the formation of CNMs. The metal nanocatalysts were characterised by SEM. Fig. 3A, B \& C are the SEM images of metal catalysts Cobalt, Iron and Nickel respectively. All the metals showed somewhat spherical structures. Since SEM microscopy was delayed the nano metals tended to fuse and thus agglomerated forms of carbon spheres can be seen in the Fig. 3 .

The Percentage Yield Of Metal Catalyst Obtained From Corresponding Metal Oxide Is Given In Table I Below.

TABLE I: YIELD OF NANO METALS FROM NITRATES OF CORRESPONDING Metals, ObTAINED By UREA DECOMPOSITION METHOD

\begin{tabular}{|l|c|c|c|}
\hline Catalyst & $\begin{array}{l}\text { Metal oxide } \\
\text { used }\end{array}$ & $\begin{array}{c}\text { Nano Metal } \\
\text { catalyst } \\
\text { produced }\end{array}$ & \\
\hline Nickel & $1.190 \mathrm{~g}$ & $0.880 \mathrm{~g}$ & 73.95 \\
\hline Cobalt & $2.603 \mathrm{~g}$ & $1.816 \mathrm{~g}$ & 69.77 \\
\hline Iron & $0.813 \mathrm{~g}$ & $0.522 \mathrm{~g}$ & 64.21 \\
\hline
\end{tabular}

Morphological analysis of CNM : The pyrolysis of sap of Calotropis plant in the presence of varying metal nanocatalyst (Nickel, Cobalt, Iron), at a temperature $900^{\circ} \mathrm{C}$, using Argon or Hydrogen as carrier gases and pyrolyzed for 2 hours led to the formation of carbon nano structures. The as-grown nanostructures were characterised by SEM 
analysis. Table II, shows the different experiments conducted and the parameters that have been varied.

TABLE II: MORPHOLOGY OF CARBON NANO MATERIALS SYNTHESIZED BY PYROLYZING CALOTROPIS SAP USING DIFFERENT PARAMETERS.

\begin{tabular}{|c|c|c|c|c|}
\hline Catalyst & $\begin{array}{l}\text { Carrier } \\
\text { gas }\end{array}$ & $\begin{array}{l}\text { Tem } \\
\mathrm{P} \\
\left({ }^{\circ} \mathrm{C}\right) \\
\end{array}$ & $\begin{array}{l}\text { Pyrolysis } \\
\text { duration } \\
\text { (hrs) }\end{array}$ & SEM image \\
\hline Nickel & Hydrogen & 900 & 2 & $\begin{array}{l}\text { Spherical } \\
\text { structures with } \\
\text { size ranging } \\
\text { from } 500- \\
900 \mathrm{~nm} \text { (Fig. } 4 \text { ) }\end{array}$ \\
\hline Cobalt & Hydrogen & 900 & 2 & \begin{tabular}{l}
\multicolumn{3}{l}{ Spherical } \\
structures with \\
size ranging \\
from $620-$ \\
$900 \mathrm{~nm}$ (Fig. 5) \\
\end{tabular} \\
\hline Iron & Hydrogen & 900 & 2 & $\begin{array}{l}\text { Irregular } \\
\text { structures (Fig. } \\
6 \text { ) }\end{array}$ \\
\hline Nickel & Argon & 900 & 2 & $\begin{array}{l}\text { Irregular carbon } \\
\text { places with } \\
\text { holes (Fig. 7) } \\
\end{array}$ \\
\hline $\begin{array}{l}\text { Without } \\
\text { catllyst }\end{array}$ & Hydrogen & 900 & 2 & $\begin{array}{lr}\text { Fused } & \text { carbon } \\
\text { particles } & \text { of } \\
\text { irregular } & \text { shape } \\
\text { (Fig. 8) } & \\
\end{array}$ \\
\hline
\end{tabular}

Impact of Nickel in presence of Hydrogen as carrier gas: The SEM micrographs (Fig. 4) shows spherical structures of varied sizes ranging from $500 \mathrm{~nm}$ to $900 \mathrm{~nm}$. The surface of the spheres appears to be rough.

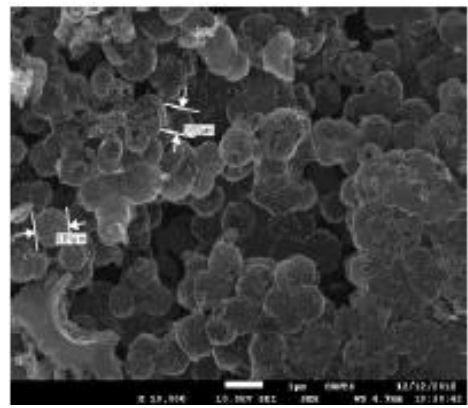

Fig. 4. SEM images of CNM obtained from Calotropis sap using Nickel as catalyst along with Hydrogen as carrier gas.

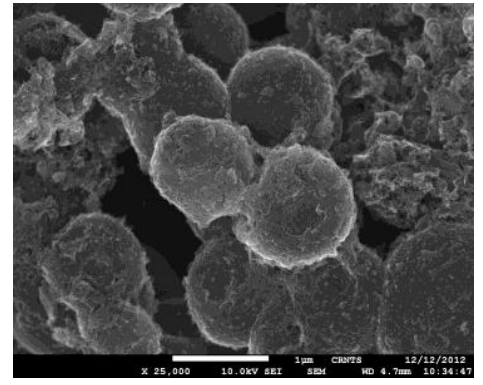

Fig. 5. SEM images of CNM obtained from Calotropis sap using Cobalt as catalyst along with Hydrogen as carrier gas.

Impact of Cobalt in presence of Hydrogen as carrier gas: The SEM micrographs (Fig. 5) also show similar spherical structures as obtained by using Nickel. The sized of carbon nano spheres varied from $620 \mathrm{~nm}$ to $900 \mathrm{~nm}$. The surface of the spheres appears to be rough.

Impact of Iron in presence of Hydrogen as carrier gas: The SEM micrographs (Fig. 6) does not show any defined structure, rather some irregular structures can be seen.

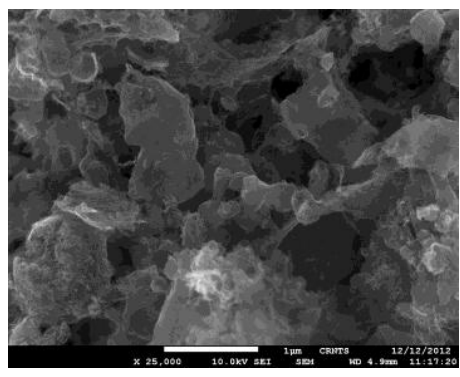

Fig. 6. SEM images of CNM obtained from Calotropis sap using Iron as catalyst along with Hydrogen as carrier gas.

Impact of Nickel in presence of Argon as carrier gas: The SEM micrographs (Fig. 7) show plates of carbon having holes in them. These holes could be due to the catalyst. However, initiation of formation of some carbon nano spheres could also be seen.

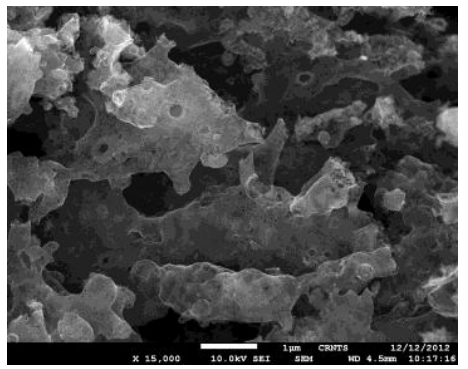

Fig. 7. SEM images of CNM obtained from Calotropis sap using Nickel as catalyst along with Argon as carrier gas.

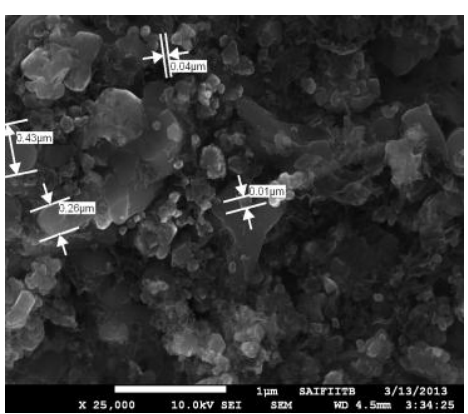

Fig. 8. SEM images of CNM obtained from Calotropis sap synthesized in absence of any catalyst using Hydrogen as carrier gas.

CNM produced in absence of any catalyst and Hydrogen as carrier gas: The SEM micrographs (Fig. 8) shows formation of fused carbon particles of irregular shapes.

The results obtained shows that Nickel and cobalt are more suited catalysts to produce defined spherical CNM using Hydrogen as carrier gas. The sizes of the CNMs vary from 10 to $900 \mathrm{~nm}$. The presence of larger sizes of CNMs can be attributed to the size of the metal nano catalyst. Hence it can be concluded that size of nanostructures can be improved, i.e. reduced by ensuring metal catalyst size remain within the 1-100nm range. Moreover, Hydrogen was a better carrier gas than argon, as Hydrogen also helped in reducing the hydrocarbons of the sap into spherical structure. Iron as catalyst did not synthesize any defined structure of carbon.

Pyrolysis of the sap without catalyst using Hydrogen gas as carrier produced mostly irregular fused nano particles; however some spherical and small structures were also seen. The smallest one was around $10 \mathrm{~nm}$. It was interesting to note the formation of nano particles even in the absence of 
catalyst. The reason could have been inherently present minerals in the sap.

The SEM analysis results give a postive indication of obtaining spherical CNM from the sap of Calotropis plant.

\section{CONCLUSION}

The sap of the Calotropis plant can be a possible precursor for synthesis of CNMs. The results obtained using the sap with Hydrogen as carrier gas at $900^{\circ} \mathrm{C}$ with Nickel catalyst is most promising. The future research will involve variation of existing as well as newer parameters to get better yield as well as better mophology of CNMs.

\section{ACKNOWLEDGMENT}

The authors acknowledge the immense encouragement and financial support given by the management of Fr. Conceicao Rodrigues Institute of Technology, Vashi, the technical support and guidance given by Prof. Maheshwar Sharon, Director of N Shankaran Nair Research Centre for Nanotechnology and Bio-nanotechnology. The authors also thank SAIF, IIT Bombay for use of their facility for analysis.

\section{REFERENCES}

[1] M. Sharon, N. Sundarakoteeswaran, P. D. Kichambre, M. Kumar, Y. Ando, and X. Zhao, "Semiconducting carbon films from a natural source camphor," Diamond and Related Materials, vol. 8, pp. 485489, 1999.

[2] M. Sharon, M. Kumar, P. D. Kichambre, N. R. Avery, and K. J. Black, "Lithium-Ion intercalation into carbons derived from pyrolysis of camphor," Molecular crystal and Liquid crystal, vol. 340, pp. 523528, 2000.

[3] M. Sharon, D. Pradhan, M. Kumar, and Y. Ando, "Nano-Octopus: A new form of branching carbon nanofiber," J. Nanoscience and nanotechnology, vol. 3, no. 3, pp. 1, 2003.

[4] M. Sharon and M. Sharon, Carbon Nano Forms and Applications, $1^{\text {st }}$ ed., McGraw Hill, USA, 2010.

[5] K. Aswasthi, R. Kumar, R. S. Tiwari, and O. N. Srivastava, "Large scale synthesis of bundles of aligned carbon nanotubes using a natural precursor: Turpentine oil," Journal of Experimental Nanoscience, vol. 5, no. 6, pp. 498-508, 2010.

[6] P. Ghosh, T. Soga, M. Tanemura, M. Zamri, T. Jimbo, R. Katoh, and K. Sumiyama, "Vertically aligned carbon nanotubes from natural precursors by spray pyrolysis method and their field electron emission properties," Applied Physics A: Materials Science \& Processing, vol. 94, pp.151-156, 2009.

[7] R. J. Andrews, C. F. Smith, and A. J. Alexander, "Mechanism of carbon nanotube growth from camphor and camphor analogs by chemical vapor deposition," Carbon, vol. 44, no. 2, pp. 341-347, 2006.

[8] P. Ghosh, R. A. Afre, T. Soga, and T. Jimbo, "A simple method of producing single-walled carbon nanotubes from a natural precursor: Eucalyptus oil," Materials Letters, vol. 61, no. 17, pp. 3768-3770, 2007.

[9] S. Karthikeyan and P. Mahalingam, "Studies of yield and nature of multi-walled carbon nanotubes synthesized by spray pyrolysis of pine oil at different temperatures," International Journal of Nanotechnology and Applications, vol. 4, pp.189-197, 2010.

[10] R. A. Afre, T. Soga, T. Jimbo, M. Kumar, Y. Ando, and M. Sharon, "Growth of vertically aligned carbon nanotubes on silicon and quartz substrate by spray pyrolysis of a natural precursor," Chem. Phys. Letts., vol. 414, no.1-3, pp. 6-10, 2005.

[11] P. Jagdale, M. Sharon, Madhuri Sharon, and G. Kalita, "Carbon thin films from plant-derived precursors," Int. J. Synthesis and Reactivity in Inorganic, Metal-organic and Nano metal Chemistry, vol. 37, pp. 467-471, 2007.

[12] S. Karthikeyan and P. Mahalingam, "Synthesis and characterization of multi- walled carbon nanotubes from biodiesel oil: green nanotechnology route," International Journal of Green Nanotechnology: Physics and Chemistry, vol. 2, no. 2, pp. 39-46, 2010.

[13] Y. Shyu and F. C. Hong, "Low temperature growth and field emission of aligned carbon nanotubes by chemical vapour deposition," Materials Chemistry and Physics, vol. 72, no. 2, pp. 223 227, 2001.

[14] Y. Ando, X. Zhao, M. Sharon, P. D. Kichambre, and M. Kumar, "Morphology of pyrolytic products from kerosene and camphor," Ann. Rep. Meizo Univ. Japan, vol. 40, pp. 95-98, 2000.

[15] M. Kumar and Y. Ando, "Chemical vapor deposition of arbon nanotubes: A review on growth mechanism and mass production," Journal of Nanoscience and Nanotechnology, vol. 10, pp.3739-3758, 2010.

[16] M. Kumar, X. Zhao, Y. Ando, S. Iijima, M. Sharon, and K. Hirahara, "Carbon nanotubes from camphor by catalytic CVD," Mol. Cryst. Liquid Cryst, vol. 387, pp. 341-345, 2002.

[17] D. Pradhan, and M. Sharon, "Carbon nanotubes, Nanofilaments and Nanobeads by thermal chemical vapor deposition process," Material Science and Engineering: B, vol. 96, pp. 24-28, 2002.

[18] R. Brukh and S. Mitra, "Mechanism of carbon nanotube growth by CVD," Chemical Physics Letters, vol. 424, pp.126-132, 2006.

[19] V. Gupta, "Synthesis of Metallic Nanoparticles and their Applications," M.S. thesis, Dept. of Chemical and Materials Engineering, Univ. of Cincinnati, 2006.

[20] C. Ducati, I. Alexandrou, M. Chhowalla, J. Robertson, and G. A. J. Amaratunga, "The role of the catalytic particle in the growth of carbon nanotubes by plasma enhanced chemical vapor deposition," Journal of Applied Physics, vol. 95, no. 11, pp. 6387-6391, 2004.

[21] N. M. Rodriguez, "A review of catalytically grown carbon nanofibers," Journal of Materials Research, vol. 8, pp. 3233-3250, 1993.

[22] S. Hofmann, K. Sharma, C. Ducati et al., "In situ observations of catalyst dynamics during surface-bound carbon nanotube nucleation," Nano Letters, vol. 7, no. 3, pp. 602-608, 2007.

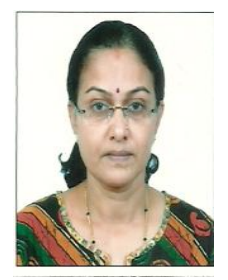

Geetha Viswanathan was born in Kerala, India on May 30, 1959. She became a member (M) of IACSIT. She did her post graduation (M.Sc.) in Physics with specialisation in Electronics from Mumbai University in 1981.

She is currently an associate professor and the head of Department of Basic sciences and Humanities at Fr. Conceicao Rodrigues Instt. of Technology, Vashi, India. She has 13 years of experience in the oil industry in the managerial capacity.

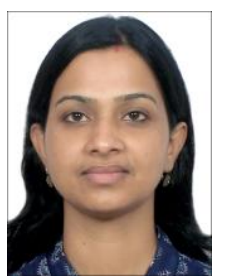

Sanjukta Bhowmik was born in Calcutta, India on December 18, 1971. She completed her doctoral work from Calcutta University in 2005 on'Platinum Thiosemicarbazide and thiohydrazide Blues'.

She is currently an assistant professor at Fr. C. R. I. T. Vashi, India. She has published 3 papers in her field of research

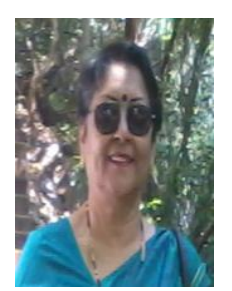

Madhuri Sharon was born in India on August 10, 1945. She has done her doctorate from Leicester, U.K in 1969 and her post doctoral work from Bolton Instt. Of Technology, U.K.

She is currently the executive director at N. S. N. Research Centre for Nanotechnology and Bionanotechnology, Ambernath, Maharashtra. She is also the managing director of MONAD nanotech Pvt. Ltd., Mumbai, India.

Dr. Madhuri Sharon has worked in several reputed multinational companies as well as educational institutes in London and India. She has coauthored three books on nanotechnology and one book on nuclear chemistry. She has published 127 papers in reputed journals. Dr. Sharon has eleven patents to her credit. She is a Ph.D. guide for four Indian universities and has so far guided sixteen $\mathrm{Ph} . \mathrm{D}$. students. 